\title{
IMPROVING MARINE VESSEL AVAILABILITY THROUGH MAINTENANCE OPTIMIZATION
}

\section{Elhussein Mohamed Eltom \\ Student}

Faculty of Engineering \& Technology

Nile Valley University, Atbara, river Nile, Sudan.

\begin{abstract}
In this research for marine vessels failures prediction, historical data of mechanical failure were collected and tabulated then analyzed by using combined seasonal and growth forecasting method and data is then fed to a curve expert software program to find the suitable model equation, which is then checked for validation by historical data, after which automated calculations of monthly average and monthly failures estimated.

Finally result calculations were discussed for wellplanned and effective maintenance program for a recourses optimization.
\end{abstract}

Keywords - dockyard; Maintenance total cost; resources optimization; availability.

\section{INTRODUCTION}

Marine vessel operation at ports is a very important part of a supply chain, with many parties involved, it is very important to avoid being the bottle neck but rather eliminate unplanned stops and maximize efficiency. The uninterrupted work of marine vessel, as downtime costs can reach thousands of Euros per hour [1]

From this point of view comes the importance of this research to have accurate prediction for machine breakdowns for effective maintenance and optimum resources utilization.

Machine break down forecasting plays an important role in maintenance management as an input for planning activities. Poor forecasting result, inefficient resource utilization and bullwhip propagating through the upstream supply chain.

By using suitable forecasting technique and proper software for accurate prediction of machine breakdowns will lead to a well-plan, effective maintenance program and optimum recourse utilization [2].

\section{LITERATURE REVIEW}

Marine vessel repair and maintenance require high capital investment in specialized equipment, such as floating docks and dry docks and cranes.

Repair and maintenance tasks need to be performed with relatively short deadlines[3].

Maintenance can be defined as the act of keeping something in good condition by checking or repairing it regularly [4].

\author{
M.I.Shukri \\ Professor \\ Faculty of Engineering \& Technology \\ Nile Valley University, Atbara, river Nile, Sudan.
}

Maintenance objectives can be summarized under four headings: ensuring the system function (availability, efficiency and product quality); ensuring the system life (asset management); ensuring safety; and ensuring human well-being [5]

Maintenance management attempts to optimize the maintenance tasks, and minimizing the repair time is an issue of optimization that comprises the availability of resources when required [6].

Maintenance optimization classification:-

During the last few decades, the maintenance of systems has become more and more complex, and an extensive amount of research has been done on maintenance optimization [7]. To reach a satisfactory result from its problems, it is essential to know the problem well and model it in the correct way. In the literature, the optimal models are classified on different parameters to various categories. These parameters could include modeling techniques, maintenance effectiveness and actions, data sources, system configuration, optimality criterion, and planning time horizon [8]. An optimal maintenance schedule should properly consider these parameters.

Maintenance-general modeling techniques are deterministic or probabilistic optimization, continuous or discrete optimization, static or dynamic optimization, constrained or unconstrained optimization, and single-objective or multi-objective optimization [9]. Maintenance-specific modeling decisions have either a component or system perspective and either a finite or infinite planning horizon [10].

Maintenance models can be categorized based on the its effectiveness work. effectiveness is the degree to which the operating conditions of an item are restored after a maintenance action is performed [11].

Maintenance can also be categorized into two major classes [12]:

corrective and preventive. Corrective maintenance $(\mathrm{CM})$ is the maintenance that occurs when a system fails. CM represents all actions performed as a result of failure to restore an item to a specified condition. Preventive work, however, is carried out to prevent failures. Preventive maintenance is plannable and is typically cheaper than corrective maintenance. The difference between corrective and preventive maintenance costs is 


\section{International Journal of Engineering Applied Sciences and Technology, 2020 \\ Vol. 4, Issue 9, ISSN No. 2455-2143, Pages 424-430 \\ Published Online January 2020 in IJEAST (http://www.ijeast.com)}

especially visible in indirect costs such as loss of production, environmental damages, or safety consequences.

The literature on maintenance optimization is abundant and contains many surveys.

For example, Cho \& Parlar (1991) surveyed the multicomponent system maintenance models[13]. The article of Dekker (1996) reviewed multi-component maintenance models, which are based on economic dependence [5]. Another extensive review was that of Wang (2002). He summarized and classified maintenance policies of single-component systems as the basis for maintenance policies of multi-component systems [11].

Carrying out an effective maintenance operation requires efficient planning of maintenance activities and resources. Since planning is performed in order to prepare for future maintenance tasks, it must be based on good estimates of the future maintenance workload [14].

Estimates of the future maintenance workload are obtained by forecasting, which can be simply defined as predicting the future. Clearly, good forecasts of the maintenance workload are needed in order to plan well for maintenance resources [15].

In order to have effective resource management, good data acquisition and methods of forecasting are required, in order to analyze the demand of the resource and to develop the proper policies. Data acquisition is the most important and usually difficult part of the process. Supposing that adequate and correct data has been collected, a simple forecast using time series analysis or other forecasting techniques[16].

\section{PROBLEM FORMULATION}

Dockyard, at Port Sudan for marine vessel maintenance suffer from uninterrupted of maintenance schedule plan and inefficient resource utilization which could be summarized in:

I) No accurate prediction for machine breakdowns.

II) Poor control in machine breakdowns.

III) Poor control in maintenance resources.

\section{Methodology}

In order to achieve the main objective of the research the following tasks were accomplished:

1. Collecting historical data and classified.

2. Data analysis.

3. From historical analyzed data the future machine breakdowns predicted by using combined seasonal and growth forecasting technique.

4. Data fed to a logic program to find suitable equation.

5. Check for validation.

6. Apply the equation to predict machine breakdown.
7. Plan for effective maintenance program.

\section{CASE STUDY}

Historical data of mechanical failures of some Sea Port Corporation S.P.C., Sudan, marine vessels components, as a case study. for the period from 2012 to 2018 were collected and classified in tables, values of each rows and columns were summed up and all tables shows twelve seasonal months across linear growth years.

Any prediction of future values has to take this seasonality into consideration, so appropriate forecasting method is combined seasonal and growth forecasting.

A logical sequence of steps to be followed when forecasting with combined seasonal and growth data are: -

1. Plot the data and visually determine any obvious time series characteristic.

2. If a growth factor such as a polynomial or an exponential is apparent, arithmetically remove it from the data, by determine an average period for each cycle and divide each data value by that average.

3. Determine if a significant seasonal trend is present in the "degrowthed data". The seasonal indices can now be found by averaging the degrowthed data over the seven years. These deseasonalized data values can then be averaged.

4. Arithmetically "deseasonalize" the original data and analyze the growth factor. The approach is to divide each datum by the appropriate seasonal index. A plot of the deseasonalize data will suggest the proper form for the growth component. These degrowthed data values can then be totals. Note that the totals for each cycle should equal the number of periods (12 in the example) If they do not, it is because of rounded- off error. This error can be doted if it is significant, by adjusting each average seasonal index.

5. Data is then fed to a curve expert software program to find the suitable model equation for average month forecast for specific year.

\section{A) Illustrative example: -}

(Motor tug ELHAMDAB main engines failures)

The plot of the historical data below shows definite growth but also seasonal pattern:

i. The year totals display no seasonality, but they do show a definite linear growth pattern.

ii. The data are seasonal, at the beginning and end months of the year are low, with higher values for the middle of the year. 
International Journal of Engineering Applied Sciences and Technology, 2020

Vol. 4, Issue 9, ISSN No. 2455-2143, Pages 424-430

Published Online January 2020 in IJEAST (http://www.ijeast.com)

Fig. No. (1) linear growth pattern of main engines, ELHAMDAB.

Failuers / Year

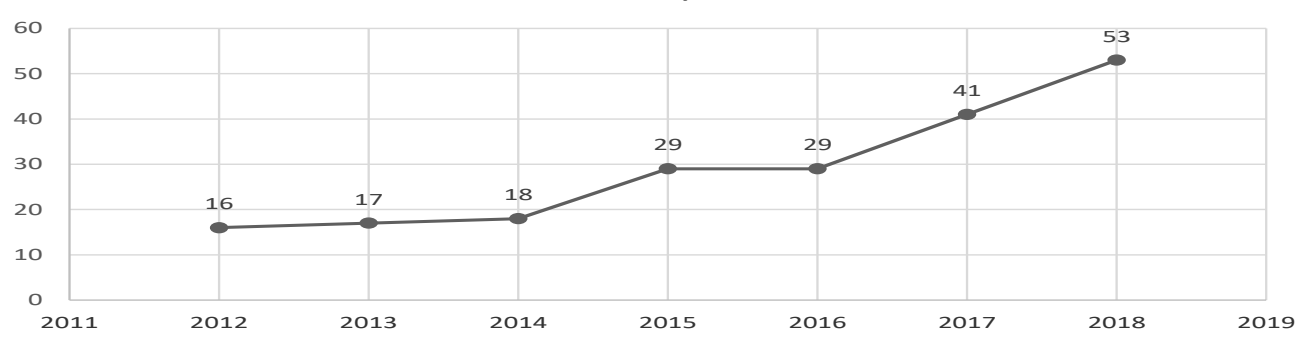

Fig. No. (2) seasonal pattern of main engines, ELHAMDAB.

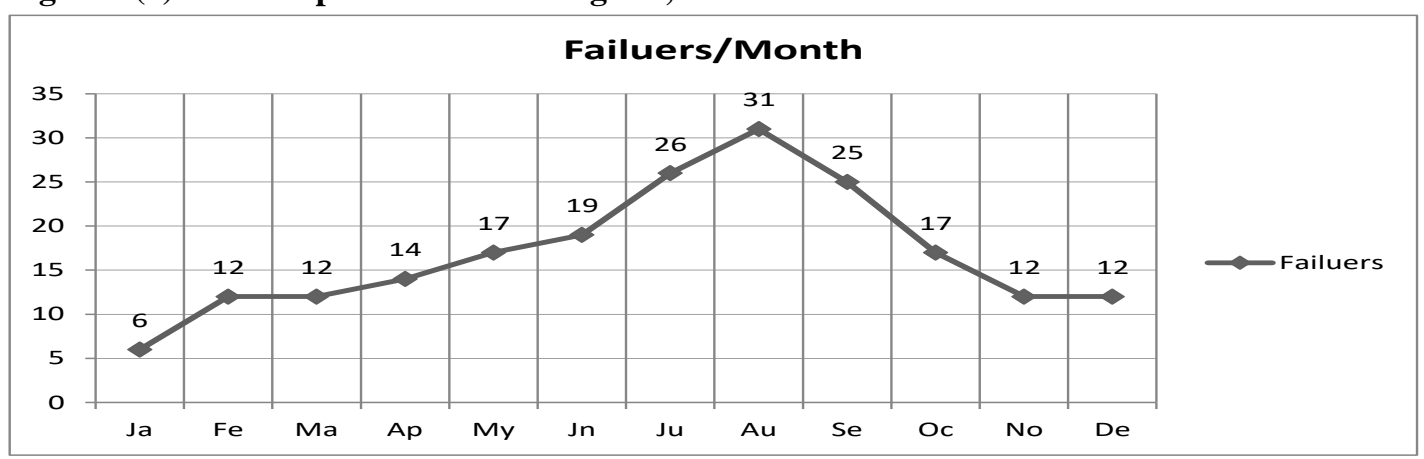

Table No. (1) Average data of main engines, ELHAMDAB.

\begin{tabular}{|c|c|c|c|c|c|c|c|c|c|c|c|c|c|}
\hline Year & Ja & $\mathbf{F e}$ & Ma & Ap & My & Jn & Ju & Au & Se & Oc & No & De & Av. \\
\hline $\mathbf{2 0 1 2}$ & 1 & 3 & 1 & 0 & 1 & 0 & 3 & 0 & 2 & 0 & 1 & 4 & $\mathbf{1 . 3}$ \\
\hline $\mathbf{2 0 1 3}$ & 0 & 0 & 0 & 1 & 2 & 5 & 1 & 5 & 0 & 3 & 0 & 0 & $\mathbf{1 . 4}$ \\
\hline $\mathbf{2 0 1 4}$ & 1 & 1 & 2 & 0 & 0 & 0 & 2 & 3 & 7 & 0 & 0 & 2 & $\mathbf{1 . 5}$ \\
\hline $\mathbf{2 0 1 5}$ & 1 & 2 & 4 & 2 & 3 & 0 & 2 & 3 & 4 & 1 & 2 & 5 & $\mathbf{2 . 4}$ \\
\hline $\mathbf{2 0 1 6}$ & 1 & 0 & 0 & 4 & 5 & 3 & 4 & 3 & 4 & 5 & 0 & 0 & $\mathbf{2 . 4}$ \\
\hline $\mathbf{2 0 1 7}$ & 1 & 4 & 4 & 3 & 3 & 6 & 6 & 6 & 4 & 2 & 2 & 0 & $\mathbf{3 . 4}$ \\
\hline $\mathbf{2 0 1 8}$ & 1 & 2 & 1 & 4 & 3 & 5 & 8 & 11 & 4 & 6 & 7 & 1 & $\mathbf{4 . 4}$ \\
\hline
\end{tabular}

Table No. (2) De-growth data of main engines, ELHAMDAB.

\begin{tabular}{|c|c|c|c|c|c|c|c|c|c|c|c|c|c|}
\hline Year & Ja & Fe & Ma & Ap & My & Jn & Ju & Au & Se & Oc & No & De & Sum \\
\hline $\mathbf{2 0 1 2}$ & 0.8 & 2.3 & 0.8 & 0.0 & 0.8 & 0.0 & 2.3 & 0.0 & 1.5 & 0.0 & 0.8 & 3.0 & $\mathbf{1 2 . 3}$ \\
\hline $\mathbf{2 0 1 3}$ & 0.0 & 0.0 & 0.0 & 0.7 & 1.4 & 3.5 & 0.7 & 3.5 & 0.0 & 2.1 & 0.0 & 0.0 & $\mathbf{1 1 . 9}$ \\
\hline $\mathbf{2 0 1 4}$ & 0.7 & 0.7 & 1.3 & 0.0 & 0.0 & 0.0 & 1.3 & 2.0 & 4.7 & 0.0 & 0.0 & 1.3 & $\mathbf{1 2 . 0}$ \\
\hline $\mathbf{2 0 1 5}$ & 0.4 & 0.8 & 1.7 & 0.8 & 1.2 & 0.0 & 0.8 & 1.2 & 1.7 & 0.4 & 0.8 & 2.1 & $\mathbf{1 1 . 9}$ \\
\hline $\mathbf{2 0 1 6}$ & 0.4 & 0.0 & 0.0 & 1.7 & 2.1 & 1.2 & 1.7 & 1.2 & 1.7 & 2.1 & 0.0 & 0.0 & $\mathbf{1 2 . 1}$ \\
\hline $\mathbf{2 0 1 7}$ & 0.3 & 1.2 & 1.2 & 0.9 & 0.9 & 1.8 & 1.8 & 1.8 & 1.2 & 0.6 & 0.6 & 0.0 & $\mathbf{1 2 . 3}$ \\
\hline $\mathbf{2 0 1 8}$ & 0.2 & 0.5 & 0.2 & 0.9 & 0.7 & 1.1 & 1.8 & 2.5 & 0.9 & 1.4 & 1.6 & 0.2 & $\mathbf{1 2 . 0}$ \\
\hline S.I & $\mathbf{0 . 4}$ & $\mathbf{0 . 8}$ & $\mathbf{0 . 7}$ & $\mathbf{0 . 7}$ & $\mathbf{1 . 0}$ & $\mathbf{1 . 1}$ & $\mathbf{1 . 5}$ & $\mathbf{1 . 8}$ & $\mathbf{1 . 7}$ & $\mathbf{0 . 9}$ & $\mathbf{0 . 5}$ & $\mathbf{0 . 9}$ & \\
\hline
\end{tabular}


International Journal of Engineering Applied Sciences and Technology, 2020

Vol. 4, Issue 9, ISSN No. 2455-2143, Pages 424-430

Published Online January 2020 in IJEAST (http://www.ijeast.com)

Table No. (3) De-seasonlize data of main engines, ELHAMDAB.

\begin{tabular}{|l|c|c|c|c|c|c|c|c|c|c|c|c|c|}
\hline Year & Ja & Fe & Ma & Ap & My & Jn & Ju & Au & Se & Oc & No & De & AV \\
\hline $\mathbf{2 0 1 2}$ & 2.5 & 3.9 & 1.4 & 0.0 & 1.0 & 0.0 & 2.0 & 0.0 & 1.2 & 0.0 & 1.9 & 4.2 & $\mathbf{1 . 5}$ \\
\hline $\mathbf{2 0 1 3}$ & 0.0 & 0.0 & 0.0 & 1.4 & 2.0 & 4.6 & 0.7 & 2.9 & 0.0 & 3.2 & 0.0 & 0.0 & $\mathbf{1 . 2}$ \\
\hline $\mathbf{2 0 1 4}$ & 2.5 & 1.3 & 2.7 & 0.0 & 0.0 & 0.0 & 1.4 & 1.7 & 4.2 & 0.0 & 0.0 & 2.1 & $\mathbf{1 . 3}$ \\
\hline $\mathbf{2 0 1 5}$ & 2.5 & 2.6 & 5.5 & 2.8 & 3.0 & 0.0 & 1.4 & 1.7 & 2.4 & 1.1 & 3.7 & 5.3 & $\mathbf{2 . 7}$ \\
\hline $\mathbf{2 0 1 6}$ & 2.5 & 0.0 & 0.0 & 5.6 & 5.0 & 2.7 & 2.7 & 1.7 & 2.4 & 5.3 & 0.0 & 0.0 & $\mathbf{2 . 3}$ \\
\hline $\mathbf{2 0 1 7}$ & 2.5 & 5.2 & 5.5 & 4.2 & 3.0 & 5.5 & 4.1 & 3.4 & 2.4 & 2.1 & 3.7 & 0.0 & $\mathbf{3 . 5}$ \\
\hline $\mathbf{2 0 1 8}$ & 2.5 & 2.6 & 1.4 & 5.6 & 3.0 & 4.6 & 5.4 & 6.3 & 2.4 & 6.4 & 13.1 & 1.1 & $\mathbf{4 . 5}$ \\
\hline
\end{tabular}

This data is fed to a curve expert software program to find the most suitable model equation for average month forecast for specific year.

Fig. No. (3) Most suitable model equation of main engines, ELHAMDAB.

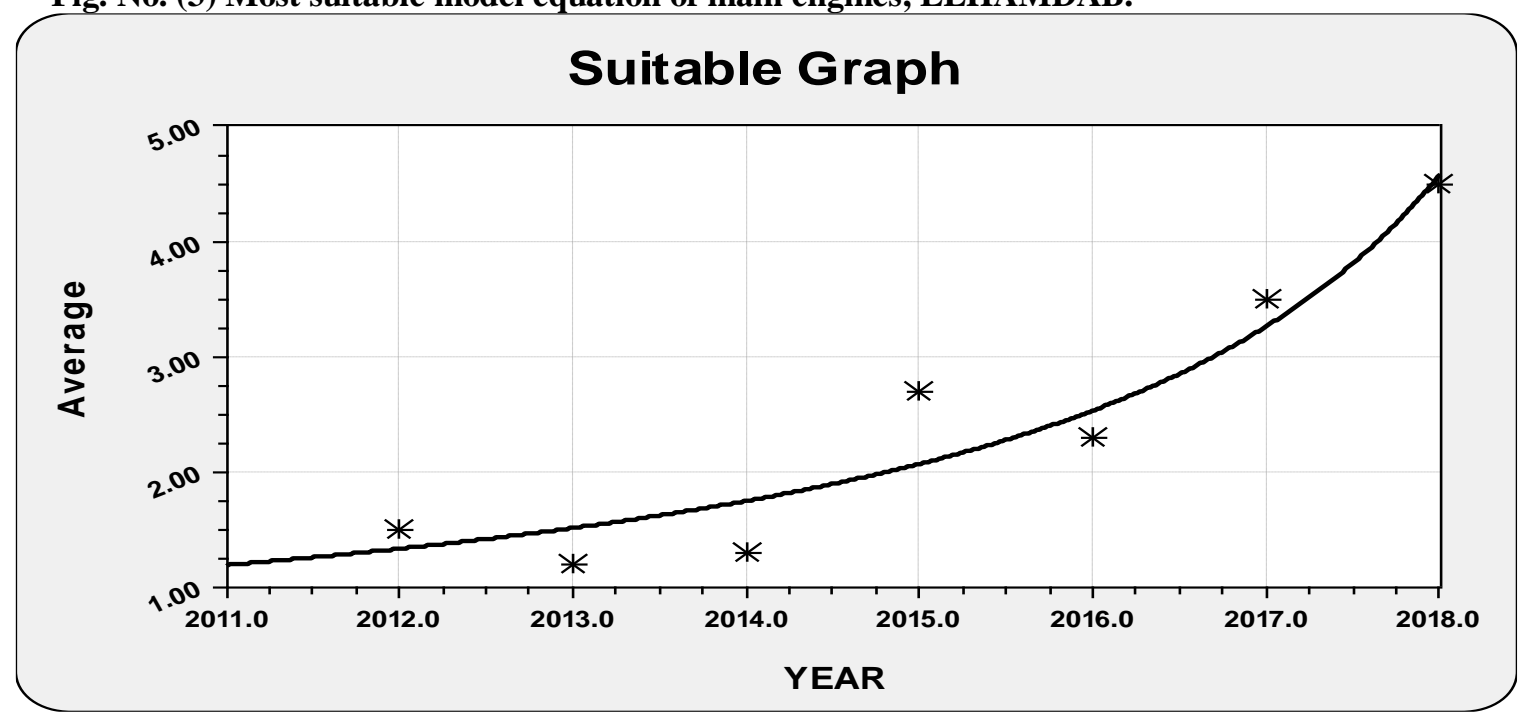

Reciprocal Logarithm Fit: $y=1 /(a+b * \ln (x))$

Coefficient Data: -

$\mathrm{a}=1.34741116443 \mathrm{E}+003$

$\mathrm{b}=-1.77055583378 \mathrm{E}+002$

Model validation: -

The suitable model equation below will be checked with the value of average of year (AV.1) for the period from 2012-2018 to verify the equations (AV.2) as shown in table below.

Table No. (4): -Average values validation.

\begin{tabular}{|r|r|r|}
\hline Year & \multicolumn{1}{|c|}{ AV.1 } & \multicolumn{1}{c|}{ AV.2 } \\
\hline $\mathbf{2 0 1 2}$ & 1.5 & 1.34 \\
\hline $\mathbf{2 0 1 3}$ & 1.2 & 1.52 \\
\hline $\mathbf{2 0 1 4}$ & 1.3 & 1.76 \\
\hline $\mathbf{2 0 1 5}$ & 2.7 & 2.08 \\
\hline $\mathbf{2 0 1 6}$ & 2.3 & 2.54 \\
\hline $\mathbf{2 0 1 7}$ & 3.5 & 3.27 \\
\hline $\mathbf{2 0 1 8}$ & 4.5 & 4.58 \\
\hline
\end{tabular}

From the table above, average values are near to each other which mean the model equation is suitable. 
International Journal of Engineering Applied Sciences and Technology, 2020

Vol. 4, Issue 9, ISSN No. 2455-2143, Pages 424-430

Published Online January 2020 in IJEAST (http://www.ijeast.com)

Implementation: -

To apply it to the period from 2019 to 2027 to estimate the forecasted defects as seen in table below.

Table No. (5): -Average values automated calculations of main engines, ELHAMDAB.

\begin{tabular}{|c|c|c|c|c|c|c|c|c|c|c|c|c|c|r|}
\hline Year & Ja & Fe & Ma & Ap & My & Jn & Ju & Au & Se & Oc & No & De & Av. & Def. \\
\hline $\mathbf{2 0 1 9}$ & 3 & 6 & 5 & 5 & 8 & 8 & 12 & 14 & 13 & 7 & 4 & 7 & 7.67 & $\mathbf{9 2}$ \\
\hline $\mathbf{2 0 2 0}$ & 9 & 19 & 16 & 16 & 24 & 26 & 35 & 42 & 40 & 21 & 12 & 21 & 23.5 & $\mathbf{2 8 2}$ \\
\hline $\mathbf{2 0 2 1}$ & -9 & -18 & -16 & -16 & -22 & -24 & -33 & -40 & -38 & -20 & -11 & -20 & -22.2 & $\mathbf{- 2 6 6}$ \\
\hline $\mathbf{2 0 2 2}$ & -3 & -6 & -5 & -5 & -8 & -8 & -11 & -14 & -13 & -7 & -4 & -7 & -7.50 & $\mathbf{- 9 0}$ \\
\hline $\mathbf{2 0 2 3}$ & -2 & -4 & -3 & -3 & -5 & -5 & -7 & -8 & -8 & -4 & -2 & -4 & -4.50 & $\mathbf{- 5 4}$ \\
\hline $\mathbf{2 0 2 4}$ & -1 & -3 & -2 & -2 & -4 & -4 & -5 & -6 & -6 & -3 & -2 & -3 & -3.50 & $\mathbf{- 4 2}$ \\
\hline $\mathbf{2 0 2 5}$ & -1 & -2 & -2 & -2 & -3 & -3 & -4 & -5 & -4 & -2 & -1 & -2 & -2.53 & $\mathbf{- 3 0}$ \\
\hline $\mathbf{2 0 2 6}$ & -1 & -2 & -1 & -1 & -2 & -2 & -3 & -4 & -4 & -2 & -1 & -2 & -2.07 & $\mathbf{- 2 7}$ \\
\hline $\mathbf{2 0 2 7}$ & -1 & -1 & -1 & -1 & -2 & -2 & -3 & -3 & -3 & -2 & -1 & -2 & -1.75 & $\mathbf{- 2 1}$ \\
\hline S.I & 0.4 & 0.8 & 0.7 & 0.7 & 1 & 1.1 & 1.5 & 1.8 & 1.7 & 0.9 & 0.5 & 0.9 & & \\
\hline Def. & $-\mathbf{- 5}$ & $\mathbf{- 1 0}$ & $\mathbf{- 9}$ & $\mathbf{- 9}$ & $\mathbf{- 1 3}$ & $\mathbf{- 1 4}$ & $\mathbf{- 1 9}$ & $\mathbf{- 2 3}$ & $\mathbf{- 2 2}$ & $\mathbf{- 1 2}$ & $\mathbf{- 6}$ & $\mathbf{- 1 2}$ & & \\
\hline
\end{tabular}

Fig. No.4: Defects per month of main engines, ELHAMDAB.

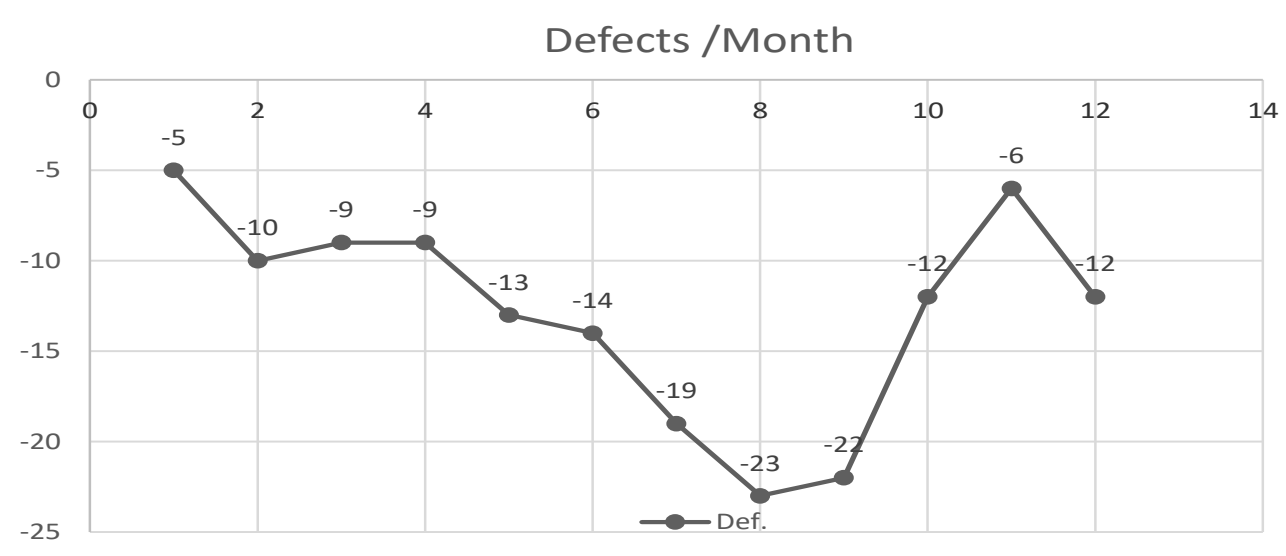

Fig. No .5: Defects per year of main engines, ELHAMDAB.

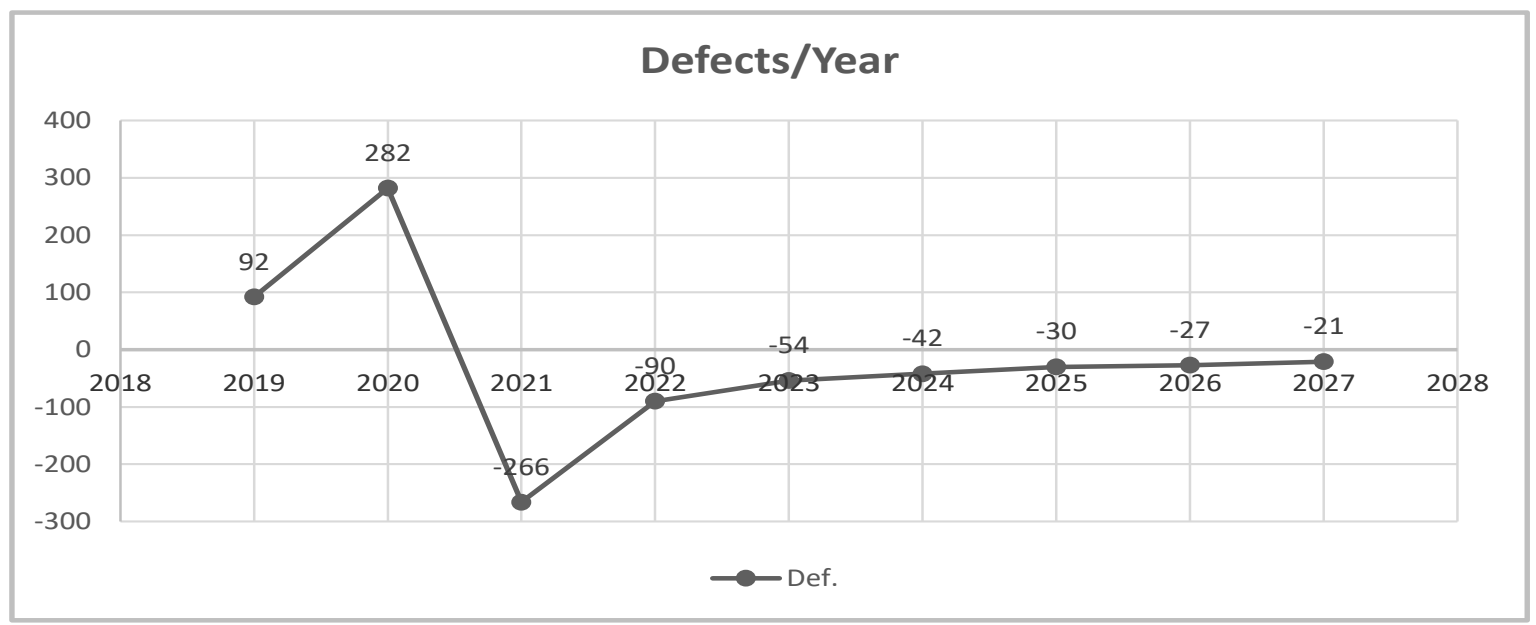




\section{International Journal of Engineering Applied Sciences and Technology, 2020 \\ Vol. 4, Issue 9, ISSN No. 2455-2143, Pages 424-430 \\ Published Online January 2020 in IJEAST (http://www.ijeast.com)}

B) Discussions:

As seen from table no 5, during next nine years no defects will be recorded unless year 2019and 2020 in which about $60 \%$ of it will be recorded in summer months (May, June, July, August and September), So recourses should be prepared during these months.

\section{LIMITATIONS AND SUGGESTION OF FUTURE WORK}

This work can be further extended to include the following:

1. This research focus only in a certain no of vessels, for more maintenance optimization, all vessels must be included.

2. For comparison, other optimization techniques can be used by another quantitative forecasting method.

3.Applying six sigma principles, DMAIC methodology, and tools such as root cause analysis for failures that has high rate and cost. 4. For mechanical failures occurrence fluctuations, its better update the research periodically.

\section{SUMMARY AND CONCLUSIONS}

This work can be summarize as follows:

- Literature was reviewed.

- The data from (2012-2018) was collected and manipulated.

- Historical data were analyzed by using combined seasonal and growth forecasting.

- Data is then fed to a curve expert software program to find the suitable model equations.

- The model equations for average month forecast checked for validation.

- Automated calculations of monthly average of the year for the period from (2019-2027) are estimated.

- Automated calculations of monthly failures done.

- Result calculations were discussed for well-planned and effective maintenance program for a recourses optimization.

\section{ACKNOWLEDGEMENT}

The authors wish to express sincere gratitude to Dr. Hag Basher Ibrahim Hag Basher and Professor Mohamed Ibrahim Shukri for their constructive comments and helpful suggestions, which lead to substantial improvements of this paper.

\section{REFERENCES}

[1] Pinha D and Ahluwailia R. (November 5-7, 2013).Decision Support System for the Ship Repair Industry, Proceedings of the 2nd Annual World Conference of the Society for Industrial and Systems Engineering, Las
Vegas, USA

(Pg

58-62).

[2] Mourtzis, D. (2005). An integrated system for managing ship repair operations, International Journal of Computer Integrated Manufacturing (Pg 721-733).

[3] Pinha, D.C.; De Queiroz, M.H.; Cury, J. E R, (2011), Optimal scheduling of a repair shipyard based on Supervisory Control Theory," (Automation Science and Engineering (CASE), 2011 IEEE Conference on, vol.39 no.44pp.24-27 Aug.2011.DOI 101109/case 2011.6042515.)

[4] James Murray, (feb 1884). Oxford English dictionary, published by oxford university.

[5] Dekker, R. (1996). 'Applications of maintenance optimization models: a review and analysis'. Reliability Engineering \& System Safety,( Volume 51, Issue 3,pp.229240).

[6] Dekker, R., Groenendijk, W. (1995). 'Availability assessment methods and their application in practice'. Microelectronics and Reliability, Volume 35, Issues 9-10. pp.1257-1274).

[7] Nicolai, R. P. \& Dekker, R. (2008). Optimal maintenance of multi-component systems: a review. In Complex system maintenance handbook (pp. 263-286).

[8] Sharma, A., Yadava, G. \& Deshmukh, S. (2011). A literature review and future perspectives on maintenance optimization. Journal of Quality in Maintenance Engineering, 17(1), 5-25.

[9] Pintelon, L. \& Van Puyvelde, F. (2006). Maintenance decision making. Acco.

[10] Van Horenbeek, A. \& Pintelon, L. (2013a). A dynamic predictive maintenance policy for complex multi-component systems. Reliability Engineering \& System Safety, 120, 39 50.

[11] Wang, H. (2002). A survey of maintenance policies of deteriorating systems. European Journal of Operational Research, 139(3), 469-489.

[12] Dhillon, B. S. (2002). Engineering maintenance: a modern approach. cRc press.

[13] Cho, D. I. \& Parlar, M. (1991). A survey of maintenance models for multi-unit systems. European Journal of Operational Research, 51(1), 1-23.

[14] Barlow, R., Hunter, L. (1960). 'Optimum Preventive Maintenance Policies'. Operations Research, Vol. 8, No. 1.

[15] Nguyen, D., Bagajewicz, M. (2008). 'Optimization of Preventive Maintenance Scheduling in Processing Plants'. Presentation. ESCAPE 18th Meeting. USA: University of Oklahoma.

[16] Narayan, V. (2004). 'Effective Maintenance Management'. New York: Industrial Press Inc. 